\title{
The Journey of Drug Dependent Persons Cared by Jail Nurses
}

Julius C. Daño

Bachelor of Science in Nursing, Cebu Normal University, Philippines.

*Corresponding author: Julius C. Daño, Bachelor of Science in Nursing, Cebu Normal University, Philippines.

Received date: February 01, 2020; Accepted date: February 10, 2020; published date: February 13, 2020

Citation: Julius C. Daño (2020) The Journey of Drug Dependent Persons Cared by Jail Nurses. J Clinical Research and Reports, 2(5);

DOI: $10.31579 / 2690-1919 / 036$

Copyright: (02020 Julius C. Daño. This is an open access article distributed under the Creative Commons Attribution License, which permits unrestricted use, distribution, and reproduction in any medium, provided the original work is properly cited.

\begin{abstract}
Nurses are hired to care for drug dependents who undergone rehabilitation. These nurses do not have sufficient training to care for the drug dependents. Having exposed to an environment where nurses are not competent in drug-dependent care may cause the drug-dependent persons to react and behave differently. Hence, this study is would like to explore live experience of drugdependent persons cared by nurses in drug rehabilitation centers. Utilizing qualitative research design specifically the descriptive phenomenological approach, the investigation revealed the following interpretive themes which aroused from their lived experiences: (a) concerned/thoughtful nurse emanates from counselling, instructing, and solicitous nurse, (b) upholding professionalism that stems from safeguarding care, warranting care, and comforting care, (c) depicting a robust behaviour that derives from reinforcing, ranting and raspy behaviour, and (d) dedicated nurse that comes from devoted, steadfast, and warmheartedness. These lived experiences of drug-dependents shows the significant essences that may convey drug-dependent persons being cared by jail nurses.
\end{abstract}

Key words: drug-dependents; jail nurses; qualitative case study; purposive sampling; semi-structured interviews

\section{Introduction}

\section{Background and Rationale of the Study}

Drug addiction is a chronic, often relapsing brain disease that causes compulsive drug seeking and use, despite harmful consequences to the drug addict and those around them. Drug addiction is a brain disease because the abuse of drugs leads to changes in the structure and function of the brain (WebMD, 2016). One of the popular drugs that cause addictions in the Philippines is Amphetamine which also includes methamphetamine It is a powerful stimulants that can produce feelings of euphoria and alertness and its effects are particularly longlasting and harmful to the brain. According to the National Institute of Drug Abuse (NIDA) (2014), drug addiction may affect the body of the users that eventually cause them to suffer lung or cardiovascular disease, stroke, cancer, and mental disorders.

Many of the Filipinos are not aware why many people are hooked to drugs and how the drugs affect the brain in order to foster uncontrollable drug use. Some of the Filipinos view the drug dependents as morally weak and they see it as a social problem. Others even believed that drug dependents can just stop using it and change their behaviour of drug use. However, there are so much to know the complexity of drug use and how to stop it. It is not merely just willpower but more is expected.

With the high rise of drug addiction, the Philippine government boldly launched the crusade to eliminate the production, distribution and use of drugs in the country. The social media (facebook, twitter, instagram,) reports resonates the movement of eliminating the illegal drug traders and users either to surrender or be killed. The Philippine newspaper reported that this drug users and drug peddlers became victims of shoot-out and summary execution by the policemen and unknown gunmen (Philippine Daily Inquirer, 2016). The results of these campaign against the drug users and drug peddlers causes a rise of mortality particularly those who are in the watch-list of the Philippine National Police through the Philippine Drug Enforcement Agency. The moved of the government causes the many drug-dependents to surrender to authorities and voluntarily submitted themselves for treatment and rehabilitation.

In the treatment and rehabilitation of these surrendering drug dependent persons, one of the care providers that assist them in the recovery are the nurses. Naegle (2006) describe nurses as uniquely positioned to deliver interventions for drug use, abuse and dependence. However, nurses dealing with drug-dependents in the rehabilitation centers lack the exposure in handling them properly. These nurses hired to work with the drug-dependents in the rehabilitation centers do not have enough experience in dealing them. In their nursing education, the Commission on Higher Education (CHED) memorandum order no 14 provides competencies for clinical/hospital and community based nursing particularly dealing with sick and well individual, family and communities. But sad to note that experience handling with drugdependents were not emphasized.

Having exposed to an environment where nurses are not competent in drug-dependent care may cause the drug-dependent persons to react and behave differently. It is assumed that the goal of helping the drug-dependents to be treated and rehabilitated will become in jeopardy. The drug dependent perceptions maybe affected to some degree if nurses are not ready to care for this drug dependent persons and they may feel strange in what is like dealing with these nurses. Hence, this study is would like to explore live experience of drug-dependent persons cared by nurses in drug rehabilitation center in order to understand the care provided by these nurses. The result of the study would be used in designing and conceptualizing nursing care plans in caring drug dependent persons as well as develop a theory to guide nursing practice. 


\section{Objective of the Study}

This research study aims to explore the lived experiences of drug dependent persons cared by nurses in drug rehabilitation centers of Cebu.

\section{Methodology}

\section{Research Design}

This study utilized qualitative research design specifically the descriptive phenomenological approach. Qualitative research is used to describe social phenomenon that is concerned with opinions, feelings and experiences of the local population as they occur naturally and understanding is sought by taking a holistic approach. It aims to grasp a more in-depth understanding of the meaning of the lived experiences of drug dependent persons who had encounters with nurses in the rehabilitation centers.

\section{Research Locale}

The Bureau of Jail Management and Penology in the Province of Cebu, Philippines shall be the location for the gathering of data.

\section{Research Sample and Sampling Technique}

Purposive sampling was utilized to identify prospective informants. It is also known as judgmental sampling wherein certain criteria are followed in order to obtain a sample and this is grounded on the belief on the researcher's knowledge of the population (Polit \& Beck, 2010). First, the researchers obtained data from the drug-dependent persons who frequently received nursing care in the rehabilitation centers. The researcher approached these prospective informants and explained to them the significance of the research. The inclusion and exclusion criteria and the informants followed the inclusion criteria of being a drugdependent, above 18 years old, being recently cared the rehabilitation nurses, in a state of consciousness and coherence, able to provide written consent, being able to speak and understand English or Cebuano language. As the informant passed the selection criteria, a scheduled interview followed.

\section{Data Gathering Procedure}

The research was approved by the Ethics Review Board (ERB) of Cebu Normal University. The changes and suggestions from the ERB were strictly followed by the researcher. After the transmittal letter was approved, a scheduled date for interview with the informants and the researcher follows. The entire interview took place inside the rehabilitation centers.

In the interview, the researcher introduced himself and explain the study's rationale, purpose, and the procedure. This is to inform the informant expectations that will happen throughout the entire session. The consent form was given to the informants and were read together with them the content of the consent form, and then the informant's affix their signature. After the consent was signed, the researcher together with the informants set the date and time for the interview.

In the interview process, three qualitative interviewing processes was used (Patton, 1990) namely: formal, conversational and semi-structured interviews. A usual technique in qualitative research is formal interview in which an initial interaction between the patient and researcher shall be done face to face with the manipulation of the venue conducive for the said activity. A conversational interview begins with the gathering of basic data of the informant such as name, age, gender, number of times visited and cared by the jail nurses, and the willingness to cooperate in the study. This would serve as establishing trust and confidence of the nurse-client relationship.

A semi-structured interview was utilized by the researcher. In this study, the semi-structured interview will be facilitated as the main source of data collection to help informants reveal their lived experience with respect to the frame of thoughts and structure of their responses. Semi-structured interview develops friendly rapport between the researcher and informant evading strange feelings of hesitation. Through this interview, the subjects can easily express their inner thoughts of their real life experiences (Dingwall, 1997). Because of this, there was a sense of flow and direction while maintaining a comprehensive exploration about the patient's feelings, thoughts, and ideas about having being cared by these jail nurses. As a result, the informants were seen as the most knowledgeable about the phenomena and they will be absolutely permitted to tell and share their own experience freely and without any interruption.

Throughout the entire data gathering process, the informants were solely interviewed inside the jail as the study is permitted based on the provisions of the rehabilitation center policies. The interview time took not be more than one hour per informant. The people beside the researcher were politely requested to keep distance so as to promote confidentiality and prevent distractions arising from any interference in the conversation from other nearby people. The manipulation of the environment must be strictly enforced because people have different behavior in different settings and this may alter the results of the study (Munhall, 2007).

Throughout all interviews, a professional conduct by the researcher were displayed to the informants. Furthermore, the researcher constantly reminds himself to eliminate his preconceived thoughts about informant's knowledge so as to prevent biased and judgmental interview questions.

Once rapport, security, and confidentiality will be attained by the researcher to the patient, he can then begin the actual phase of the gathering of data through a semi-structured interview. The entire interview were accomplished within 30 minutes or until data saturation is attained as identified by the researcher.

\section{Data Analysis}

Guided by the principle of bracketing (Gearing, 2004), results of the interview were treated in this manner. There are three forms of bracketing that will used in the study namely descriptive bracketing, existential bracketing and pragmatic bracketing.

Descriptive bracketing allows the researcher to clearly set aside the base majority of personal suppositions and hold in abeyance most external suppositions, thereby focusing on the pure essences of the phenomenon but recognizes that it might not always be possible to bracket out some of the larger social and cultural elements of the world and social interaction (Gearing, 2004).

In existential bracketing, the researcher is unable to bracket out the suppositions of the larger world or environment. The temporal structure element is erected loosely so that the researcher can investigate the phenomenon without ready-made interpretations or theories. It tries to seek the essence of the story that can be referred to the coding of data into themes, analyzed in order to uncover the central meaning of the "essence" of the phenomenon. The researcher is afforded wider latitude in establishing the star point, duration, and end point but should define these components clearly prior to the onset of their investigation (Gearing, 2004).

Pragmatic bracketing rests on the researcher's individual approach and his or her self-identified focus. Researchers often construct 
such bracketing to fit their research questions, investigation, or analyses. . Pragmatic bracketing remains effective when researchers effectively identify and describe the composition and function of this form of bracketing, drawing from theory and prior research.

The whole process will be based on the data, transcribed interviews, sorting, categorizations (cool analysis), categories as thematized (warm analysis) in a repertory grid or a dendogram that shall pave the way to discovering the value of the lived experiences of stroke patients in a medical unit cared by male and female nurses.

The researcher followed the seven steps of analysis with inclusion of additional step as proposed by Colaizzi in 1978 (Edward and Welch, 2011). The first step is transcribing all the subjects' descriptions. In this section of the analysis process, participant narratives are transcribed from the audio-taped interviews held with each individual. According to Colaizzi's (1978) process, the narratives do not need to be transcribed verbatim, as long as the essence of what the participant was communicating is caught in the transcription. Individual transcriptions of interview are then validated by the respective participant.

The second step is extracting significant statements [statements that directly relate to the phenomenon under investigation]. Any statements in the participants' narratives that relate directly to the phenomenon under investigation are considered significant. Significant statements are extracted from each of the narratives and numbered. The significant statements are numerically entered into a list (i.e., I1, I2, I3, I4 ...) that is, an assemblage of all significant statement

The third step is creating formulated meanings. In this stage of analysis, Colaizzi (1978) recommends that the researcher attempts to formulate more general restatements or meanings for each significant statement extracted from the participant's narratives.

The fourth step is aggregating formulated meanings into theme clusters. Colaizzi (1978a) suggests that the researcher assign or organize formulated meanings into groups of similar type. In other words, the formulated meanings are grouped into theme clusters. That is, some statements may relate to, for example, faith while other statements relate to self-awareness and so on.

The fifth step is developing an exhaustive description [that is, a comprehensive description of the experience as articulated by participants]. An exhaustive description is developed through a synthesis of all theme clusters and associated formulated meanings explicated by the researcher (Colaizzi, 1978a). The sixth step is additional step, this is the researcher interpretative analysis of symbolic representations - from the articulation of the symbolic representation (which occurred during participant interview).

The seventh step is identifying the fundamental structure of the phenomenon. The fundamental structure refers to 'the essence of the experiential phenomenon as it is revealed by explication' through a rigorous analysis of the exhaustive description of the phenomenon.

And the eight step is returning to participants for validation. A follow-up appointment is made between the researcher and each participant for the purpose of validating the essence of the phenomenon with participants. Any alterations are made according to participant feedback to ensure their intended meaning is conveyed in the fundamental structure of the phenomenon. Integration of additional information provided by participants for inclusion into the final description of the phenomenon occurs at this point.

\section{Ethical Considerations of the Study}

In order to guide the research to fulfil the preliminary and current topics coming from qualitative research, ethical principles were observed. The observation of well-known ethical principles, specifically, autonomy, justice, and beneficence should be of top priority to alleviate the intrinsic problems of qualitative research. As a result of this usage, the goals of the research can be adequately realized and at the same time, the rights of the research informants can be preserved (Orb, Eisenhauer \& Wynaden, 2000). In addition, there needs to be a harmonious balance between the research philosophies and the informant's wholeness (Ramos, 1989).

The informed consent indicating the use of the audiotape in the interview process was emphasized. Aside from the use of audiotapes, diaries and field notes was used to further add more information during the gathering of data. Non-verbal cues shall be noted by the researcher's assistant and a summary of each informant's answers shall be recorded so that they can be easily remembered.

The patient was reassured that their identity will always remain confidential and that they will be assigned fictitious names. After each interview, the researcher listened to the recording and then transcribed to a digital document for prompt documentation. Afterwards, the copy were analyzed so that there will be some realizations and understandings about the phenomenon. This was read and re-read so that meaningful quotes will be identified. Then, these quotes were grouped into themes.

According to the 1987 Philippine Constitution, particularly article XIV, section 6 and 7, the national language of the Philippines is Filipino and English (Tan, 2014). Thus, the interview utilized the mixture of English and Cebuano language to facilitate communication and understanding between the researcher and the informant. The response of the informant was likely in English and Cebuano as this interview was in a Cebuano-speaking region. In order to get a great deal of clarity in the translation from Cebuano-English to pure English, a linguist expert were consulted. The expert translated the Cebuano-English words into English. Once this is done, the transcription was read and verified by the informant, taking note that the content and message of the interview shall not be altered due to the translation. The signature of the informant shall then be affixed in the transcription indicating that the translation was correct and unbiased. Because of this, the gathered information is still intact and this will maintain the validity of this research.

The researcher provided an informed consent to the informants. It contained the focus of the study, significance, and goals. Moreover, it emphasizes the right to refuse in the participation of the study so that the interview with the informant shall not be intimidated by the researcher. According to Capron (1989), respect for people is the acknowledgment of the rights of the informant, which includes the right to be notified about the study beforehand, the right to choose whether to participate in a study without restrictions, and the right to discontinue in the participation at any time without consequence.

Fictitious names were assigned to each informant to conceal their identity. This must be of utmost importance since this can prevent any form of harm and any other unwanted events towards the informants. Strict confidentiality of the collected data were kept in a secure box in the house of the researcher. The documents was opened when the researcher is alone at the room of the house. Only the patients themselves and the research team shall be allowed to view and edit the files of the interview. Moreover, the audiotaped recording will be locked with a given password so no one can inadvertently listen to it without the researcher's knowledge.

\section{Demonstrating Trustworthiness and Rigor of the Study}

According to Whittemore and colleagues (2001), four primary criteria arise in qualitative studies while six secondary criteria can deliver additional standards of validity but these are irrelevant to each research. This study achieved the central goal of validity with the utilization of Whittemore and colleagues' criteria. Throughout the entire course of the study, writing down reflexive journals and careful documentation shall be of primary importance. Because of this, there will be an improvement in 
the researchers' credibility through efforts to become spontaneous. Moreover, this shall lead to accounting his own perception and prejudices.

The rigor of the study was enhanced with the use of constant observation, utilization of comprehensive field journals, and permitting opportunities for short pauses towards the informants in times of prolonged engagement. During the interview in which the informant was given consent, an audiotape and field notes containing the non-verbal cues and summaries of each answer will improve the vividness and explicitness of the study. Explicitness is defined as the skill of following the researcher's choices and explanatory efforts by means of preserving records cautiously and presenting outcomes comprehensively. Meanwhile, a presentation of rich, clear, authentic, and crafty depiction that highlight the striking themes in the data define vividness (Polit \& Beck, 2008).

In order to strengthen the credibility of the study, a member check was done wherein he gave reaction to the study informants about the developing analyses and obtain each informant's feedbacks. Member checking was done constantly while data are being gathered and more formally after data analysis has been fully realized. Through joint decision-making, there will be a reduction of possibility biased conclusions and idiosyncratic interpretations of the records.

The use of quality enhancement strategy was employed in external validation. Different sessions with the fellow students who are knowledgeable in the methods of true-to-life review which can then evaluate and explore various aspects of the study will be done by the researcher. A rich, comprehensive, and clear description of the research framework, the experiences, and the developments observed during the study will be delivered by the researcher during the presentation of the data. As a result, the essence and themes that appeared from the study was widely supported by comprehensive coding and transcriptions from the participants. The researcher's qualifications, experience, and reflexivity will also be shown in the study.

\section{Results and Discussion}

The investigation into the phenomenon of drug-dependent persons cared by jail nurses revealed the following interpretive themes which aroused from their lived experiences: (a) concerned/thoughtful nurse emanates from counselling, instructing, and solicitous nurse, (b) upholding professionalism that stems from safeguarding care, warranting care, and comforting care, (c) depicting a robust behaviour that derives from reinforcing, ranting and raspy behaviour, and (d) dedicated nurse that comes from devoted, steadfast, and warm-heartedness. These lived experiences of drug-dependents shows the significant essences that may convey drug-dependent persons being cared by jail nurses.

\section{Conscientious Nurse}

The key informants see their nurses perform their task and responsibilities carefully. They make sure that wellness and health among the drug-dependents were uphold all the time. By showing their interest in caring the drug-dependents, giving them health instructions in preventing disease formation, and providing them the proper guidance in making healthy decisions that would ease them are the behaviour of nurses observed by their drug-dependents.

\section{A Counselling Nurse}

The key informants realized that the nurses were very helpful to them especially in counselling them in making wise decisions. The nurses were so serious in sparing the drug-dependents from unhealthy practices like smoking or other unhealthy related activities. They say that:
"When I would have a cough, she'd tell me to refrain from--- So she'd say, "Stop smoking, don't talk, and behave accordingly. I should be formal. I should shave, keep calm"

"He just talks to us calmly like he would explain our condition through the medications that he would give."

"Next time, if you would be free, please refrain from indulging in these kind of activities. Please live peacefully and take good care of your children."

\section{An Instructing Nurse}

The nurses in the jail facility were perceived by the key informants as one who provide them important information that would make them practice healthy lifestyle. The key informants grasp the thoughtful instructions given by their nurses. They say:

"You should follow this. Your diet should be like this.

She would inform you." Like, "I won't give you one. I don't care if you would get angry with me."

She would really impart new insights about smoking. She has shared this to a lot of people who---

\section{A Solicitous Nurse}

The nurses were perceived by the key informants as careful in their care by showing interest or concern among them. Being considerate is very helpful with the drug-dependents because they still perceived it as one who is attentive and mindful to their lives inside the jail facility. They say that:

"They won't know at first but when they would ask me, "Have you drank your medicine?"

"She would approach you if you have any complains."

"She would really assess you and she would never leave you."

\section{Upholding Professionalism}

The key informants observed the jail nurses uphold their professional conduct in the performance of their duty. Amidst the pressure of many problems the drug-dependents are facing, the jail nurses maintain their composure to fulfil their oath of professionalism. These nurses exercises their safeguarding duty that guarantees warranting and comforting care.

\section{Safeguarding behavior}

The jail nurses projected a safeguarding behaviour as perceived by the drug-dependents. As provided in the standards of nursing practice, one of the responsibilities of the nurses is to make sure that "the patients' health are check, monitored and evaluated all the time as long as they are in their care." The key informants observed that nurses are doing their best in making sure that their health are well guarded. They say:

"They are very alert and responsive. Yes, especially with the problems of drug dependent patients. So they do check-ups every week

"They brought me to the clinic. They welcomed me sir and attended to me sir. They took my BP and the nurse then said, "What, you have a very high blood pressure."

"The way the deal with me is that they watched me closely with the nurse, yes. He asked me with what I am feeling."

\section{Warranting Care}

The key informants see that the care they received by the jail nurses are warranted for health guarantee. The actions of the jail nurses in guaranteeing care were perceived by the drug-dependents as a clear 
message that helping them in promoting health and preventing illness is a serious matter. They say:

"they made me a referral whether I would be checked up."

"When I was having a difficulty in breathing, they would tell me... just like this, they would interview me .He asked me with what I am feeling. Yes. He asked, "What are you feeling?" I replied to him, "My legs has lost its strength sir." That's why... he replied, "Just get a form so that it would be filed to the court so you would have your check-up."

"And some nurses would also conduct assessments and we would give them our health records."

"So that she would be sure that the patients would be given their daily maintenance. Yes, that's the only thing that the nurse gave me and she if I asked for another, she won't allow I would not take more medications because it would cause harm."

\section{Comforting Nurse}

The key informants perceived the jail nurses as comforting nurses. They realized that the care provided by these jail nurses cause the drug-dependents to worry less and giving them the ease they desire and give them strength and hope to times of sorrow. They say:

"When they would understand my condition through my history, they'd give me the opportunity to stay outside, right here, so that I can breathe fresh air."

"They are not that strict when you would not be feeling well."

"The nurse let me relax and sit in a chair. She gave me time to breath."

"The nurse assisted me sir. The nurse said, Let him stand, let him rest in the chair near the door--- So that he can breathe comfortably. It alleviated my condition sir."

"So they placed me comfortably and they give me a sublingual medication."

\section{Robust Personality}

The jail nurses were perceived by the drug-dependents as one with robust personality. They see these jail nurses' exhibit strength or vigor in the performance of their duty. As jail nurses, they make sure that they project an able-body, bouncing and fit personality to guarantee authority over the drug-dependents. These projections of the nurses shows the security figure of being also designated as a jail guard.

Reinforcing Behaviour. The jail nurses caring for drug-dependents were perceived as one who strengthens the health practices. These jail nurses bolster and shore up the health behaviours of the drug-dependents. These action of the nurse's guarantees that care is well provided and making sure that the health of these drug-dependents are strongly reinforced. They say:

"Damn, you forget taking your medicine. Take it now, take it."

"Why won't anyone take a bath when there's water."(with a loud thundering voice)

"Come over to the station Mister, Its time to take you medicines"

\section{Ranting Behaviour}

The jail nurses were observed by the drug-dependents with ranting behaviour. The drug-dependents noticed that every time they failed to regularly perform the task, the jail nurses talk loudly in a way that shows anger. The spout behaviour of nurses is a reflection of frustration that the drug-dependents are not doing the expected things in the rehabilitation center. They say

"They would get angry. That's the time that the nurse's voice would raise. He would get mad sir"
"He would just say, "Please, please, please be clean with your bodies because in the end, you would suffer the consequences. You would get sick and in turn, you would go back here in the---"

"Sounds like but with a little sarcasm. There are times that he would be in high temper."

\section{Raspy Behaviour}

The jail nurses were seen as having a raspy behaviour by the drug-dependents. The irritable and quick-temperament of the nurses were noticed when the drug dependents do not follow their instructions. These raspy behaviour depict that nurses are serious in really looking at the drugdependents as their client of care. They say:

"She also gets mad if the prisoners won't follow her instructions like, "Don't keep on taking the medicines because it's harmful and greatly affects the kidney."(with harsh sounds)

"She would say to us, "I wouldnt be giving medicines that much especially antibiotics. Because antibiotics greatly affect our kidney." That's why the nurse won't just give medicines right away especially if there are no prescriptions."(accompanied with a grating sounds)

\section{Dedicated Nurse}

The drug dependents perceived the jail nurses as dedicated nurse. They see these nurses adhere to their duties they pledge to be as health care provider in the jail facility. Nurses swear to oath indicating their commitment to patient care and professionalism. These commitment were greatly perceived by the drug-dependents being care by the jail nurses.

\section{Devoted Nurse}

The jail nurses were perceived by the drug dependents as being loyal to their duties and responsibilities. Nurses devote themselves to care of the sick drug dependents in the jail facility. When drug dependents need the care from the jail nurses, they always received affectionate and loving care. They say:

"she would devote her time with you."

"I could easily reach out to her in a way that---I can interact with her. Yes, I can relate also with her. I can easily talk with her."

\section{Steadfast Nurse}

The drug dependents see the jail nurses as one who is firm and determined in doing their duties and responsibilities. The steadfast nurses shows the steady and unwavering course in rendering the care to the drug dependents. The drug dependents perceived these nurses as professionals who really perform their duties with firm belief and conviction. They say:

"Whenever I am severely sick, she made me a note to be given to the lawyer so that I will be allowed for my ultrasound exam."

"She would really get the prescriptions especially those obtained from the outside."

\section{Responsive Nurse}

The jail nurses were perceived by the staff nurses as one who reacts to health situations in a desirable way. These responsiveness of jail nurses in doing their care to the drug dependents is grounded on the elements of mutual respect and trust. They say:

"The nurse would approach them right away so that she can intervene right away." 
"Yes. The nurse frequently monitored me... ahh, I underwent prenatal and ultrasound."

\section{Discussion}

This study shows how drug dependents experience caring from nurses in the drug rehabilitation centers in the Province of Cebu, Philippines. For drug dependents, their experiences were very inspiring as it shows many profound phenomenon that is more meaningful and rewarding as they were being helped by the nurses in the rehabilitation centers.
From a rationale perspective, the attitudes of nurses in the rehabilitation centers were seen by the drug-dependents as something positive (Crothers and Dorrian, 2011) (Feghihi, 2016). These positivism stems from the attitudes of nurses as there is an increasing recognition about drug use and their knowledge about the reasons of drug-addiction (Goldmann, 2008). The nurses positive attitudes indicates how they like helping the drug dependents and felt they are being appreciated (Gorman, 1991).

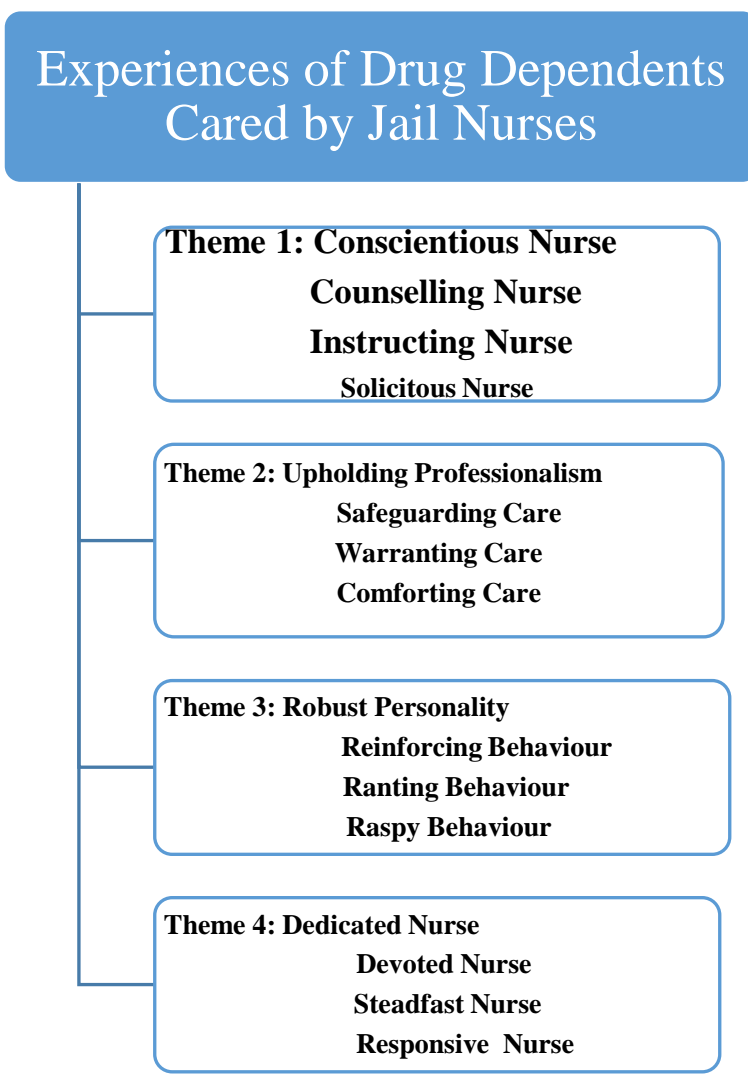

Figure 1. Diagram of Experiences of Drug-Dependents Cared by Jail Nurses

As rehabilitation nurses working with drug-dependent persons, it cannot be helped and controlled the violence that happened in the rehabilitation centers. According to the Guardian (2015), the violence comes in many forms where the nurses became victimized and traumatized by it. This makes nurses become hyper-vigilant, even though they have control in the rehabilitation centers but yet they don't have the control because the drug-dependents sometimes run the rehabilitation centers. The drug-dependent could be compliant to the demands of the rehabilitation centers policies but sometimes they choose not to be. The hyper-vigilant behaviour of nurses project a fearful stance in order to prevent from being manipulated by the drug-dependent persons.

Figure of authority projected by the nurse is important in order to prevent chaos in the rehabilitation centers. However, according to Zimbardo (1999), these authority figures should not be abused and should not take these authority as the final deciding factor in a making actions or decisions. The nurses in the rehabilitation centers are still conscious of the morals which play a big role in their decision-making processes as they dealt with the drug-dependent persons. Moreover, the professional nursing mandates (RA 9173: Code of Ethics) nurses to be an ethico-moral nurses that adheres to the Code of Ethics of Nurses and abide its provision. It is imperative therefore that nurses in the rehabilitation centers exercise all its authorities as mandated by the laws with utmost respect and dignity to the drug-dependent persons.

The nurses upholding professionalism as perceived by the drugdependents resonates caring behaviours more often than being reported by patients being cared by them. Modic, Siedlecki, \& Quinn describe giving and providing the patients the best experience in their care is the utmost priority of nursing. It is a "care that addresses every aspect of patients' encounters, including their physical comfort, as well as their educational, emotional and spiritual needs." It is about drug-dependents being valued, being connected to reality and promote a well collaborated means of providing the best outcome in all situations.

Nurses were perceived as adviser that explains the care provided and reassures the drug dependents on their safety and needs. As devoted nurses, Weyant, Clukey, Henderson, and Roberts (2017) describes caring personalities such as an educator, being with the drug dependents in times of need, shows great skill in the performance of task 
and their ability in implementing quality nursing care are qualities of good nursing. Nurses in the rehabilitation centers uphold their oath to do no harm and practice the nursing profession faithfully. With the caring contribution of nurses to the drug dependents, it attains an array of positive health and social care outcomes.

The drug dependents sees nurses as teachers, educators, and instructors in the rehabilitation centers. These nurses provide them information that is beneficial to the health of the drug-dependents. According to the Public Health England, teaching, leadership, clinical and quality improvement are the essential component parts of the nurse role in working with the drug-dependents. It is maintained that the core functions of nursing in the rehabilitation centers is providing information's significant for the promotion of health and prevention of illness among the drug dependents.

The most significant aspect that greatly affects the lives of the drug-dependents in the rehabilitation centers is the kind of nurse-patient relationships. The nurses are in the better position to facilitate the drugdependents biopsychosocial needs and promote a very warm environment that makes a therapeutic rehabilitation centers. As Merriam-Webster defined relationship as "the way in which two or more people or things are connected or interrelated." The nurse-patient relationship is a main element that provides betterment drug-dependents (Courey, Martsolf, Draucker, \& Strickland, 2008). Thus, the perception of drug dependents that nurses in the rehabilitations centers demonstrate care such as responsiveness, being encouraging (Johansson et al., 2002), and displays respect and empathy (Shattell, 2004) is a reflection that nurses do care.

The nurses were felt by the drug dependents as advisers in times of need. These drug-dependents felt that they feel comfortable and able to understand situations that hounds them inside the rehabilitation centers. These counselling of nurses helped the drug-dependents reduce anxiety and felt being respected. When nurses gives advises to the drugdependents, judgment and predetermined ideas were not part in the process, thus this strengthen the credibility of nurses doing the job (Sleeper and Bochain, 2003).

\section{Conclusion}

As drug dependents placed in the rehabilitation centers, it is but normal to feel the many insecurities they encountered. But the findings of the study revealed that the drug-dependents being cared by nurses in the rehabilitation centers perceived nurses as very caring and helpful to their needs. They felt their health is secured in the rehabilitation centers with nurses attentively attending their needs. With the findings of the study, jail nurses are well valued by the drug dependents amidst their multitasking job in the rehabilitation centers.

\section{References}

1. Benner; Patricia, Hughes; Ronda G., and Sutphen, Molly. (2006). Patient Safety and

Quality: An Evidence-Based Handbook for Nurses. Rockville (MD): Agency for

Healthcare Research and Quality (US); 2008 Apr.

2. Cohen D, Crabtree B.(2006). Qualitative Research Guidelines Project.

3. Commission on Higher Education. (2009). Circular Memorandum No. 14.

4. Crothers, C. E. and Dorrian, J. (2011). Determinants of Nurses' Attitudes toward the Care of Patients with Alcohol Problems. ISRN Nursing Journal.
5. Courey, T. J., Martsolf, D. S., Draucker, C. B., \& Strickland, K. B. (2008). Hildegard Peplau's theory and the health care encounters of survivors of sexual violence. Journal of the American Psychiatric Nurses Association, 14(2), 136-143.

6. De Clerck H., Willems R., Timmerman C., \& Carling J., (2011). Instruments and guidelines for qualitative fieldwork.

7. Fraser, Jennifer A. and Barnes, Margaret and Biggs, Herbert C. and Kain, Victoria J. (2007) Caring, chaos and the vulnerable family: Experiences in caring for newborns of drug-dependent parents. International Journal of Nursing Studies 44 (8):pp. 1363-1370.

8. Feghihi, F. (2016). Study of Relationship Between Attitude and Practice of Nurses in the Care of Drug-dependent Patients Admitted in Public Hospitals of the City of Yasouj, Iran 2014. Acta Medica Meditarranea. Retrieved on May 22, 2018.

9. N. Friesen et al. (eds.), Hermeneutic Phenomenology in Education, 1-14. (C) 2012 Sense Publishers.

10. Greene, D. (2009). An investigation of patient experiences of treatment in the cranial field of osteopathy New Zealand (pp. 22-23).

11. Goldberg, Joseph (2016) on Meaning of Drug Addiction.

12. Goldman, D.F. (2008). Genetic approaches to addiction: genes and alcohol. Addiction.

13. Gorman DM, Cartwright AKJ. (1991). Implications of using the composite and short versions of the Alcohol and Alcohol Problems Perception Questionnaire (AAPPQ) British Journal of Addiction.

14. Hair J., Wolfinbarger M., Ortioau D.,\& Bush O., (2010). Essentials of Marketing Research.

15. Happell, Brenda, Wynaden, Dianne, Tohotoa, Jenny, et al (2014) Mental Health lived experience academics in tertiary education: The views of nurse academics, Nurse Education Today.

16. Hughes, Ronda G. (2008). Patient Safety and Quality: An Evidence-Based Handbook for Nurses.

17. providers/resources/nursing/resources/nurseshdbk/nurseshdbk. pdf on January 6, 2017.

18. Johansson, P., Oleni, M., \& Fridlund, B. (2002). Patient satisfaction with nursing care in the context of health care: A literature study. Scandinavian Journal of Caring Sciences, 16, 337-344.

19. Kongsuwan, Waraporn. (2009). Thai Nurses Lived Experiences of Caring for Persons Who had a Peaceful Death in Intensive Care Units.

20. Locsin, Rozzano C. and Matua, Amandu Gerald. (2002) The lived experience of waiting-to-know: Ebola at Mbarara, Uganda - hoping for life, anticipating death. Journal of Advanced Nursing Volume 37, Issue 2, pages 173-181.

21. Ludwig, Mary Ann; Marecki, Marsha; Wooldridge, Powhatan J.; Sherman, Laura M. (1996). Neonatal Nurses' Knowledge of and Attitudes Toward Caring for Cocaine- Exposed Infants and Their Mothers.

22. Mannen, M. V. (1997). Qualitative health research. From Meaning to Method, 345-369.

23. Modic, M.D., Siedlecki, Sandra, Quinn Griffin, M.T. Caring behaviors: Perceptions of acute care nurses and hospitalized patients with diabetes. Journal of Patient Experience. Accessed at on May 21, 2018.

24. Naegle, Madeline A. Compentencies for Nursing Care of Patients with Substance

Related Disorders. 
25. National Institute of Drug Abuse (2014), on Drugs, Brains, and Behavior: The Science of Addiction.

26. Philippine Regulation Commission. Board of Nursing. Republic of the Philippines.

27. Polit, D. F. \& Beck, C. T. (2008). Nursing research: Generating and assessing evidence for nursing practice. Analyzing Qualitative Data, 507-535.

28. Public Health England. The Role of Nurses in Alcohol and Drug Treatment Services. Retrieved on May 21, 2018.

29. Tomey, Ann Marriner \& Alligood, Martha Raile. (2008). Nursing Theorists and their Work. $6^{\text {th }}$ ed. Mosby Elsivier.

30. Scriven M, Paul R. Defining critical thinking. 2006.

31. Shattell, M. (2004). Nurse-patient interaction: A review of the literature. Journal of Clinical Nursing, 13, 714-722.

32. Siegle, D. (2002). Qualitative Research - Educational Research.

33. Sleeper J.A. \& Bochain S.S. (2003). Stigmatization by nurses as perceived by substance abuse patients: A phenomenological study. Journal of Nursing Education and Practice, 2013, Vol. 3, No. 7.

34. Sloan, A. \& Bowe, Brian (2014). Phenomenology and hermeneutic phenomenology: the philosophy, the methodologies and using hermeneutic phenomenology to investigate lecturers' experiences of curriculum design. Quality \& Quantity, Vol.48, no.3, pp.1291-1303.

35. Van Manen, M. (1997). Researching lived experience: Human science for an action sensitive pedagogy. (2nd ed.). London: The Althouse Press.

36. Weyant, R.A. Clukey, L., Henderson, A. and Roberts M. (2017). Show Your Stuff And Watch Your Tone: Nurses' Caring Behaviors. American Journal of Critical Care.

37. Zimbardo, Philip K. (1999). "The Stanford Prison Experiment." Writing and Reading

38. Across the Curriculum. Ed. Laurence Behrens and Leonard F. Rosen. New York: London, 348-358.

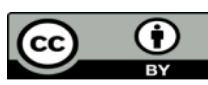

This work is licensed under Creative Commons Attribution 4.0 License

To Submit Your Article Click Here: Submit Manuscript

DOI: $10.31579 / 2690-1919 / 036$.
Ready to submit your research? Choose Auctores and benefit from:

* fast, convenient online submission

* rigorous peer review by experienced research in your field

* rapid publication on acceptance

* authors retain copyrights

* unique DOI for all articles

* immediate, unrestricted online access

At Auctores, research is always in progress.

Learn more www.auctoresonline.org/journals/journal-of-clinical-researchand-reports 